\title{
Investigating the impact of teacher education strategies on preservice teachers' TPACK
}

Article in British Journal of Educational Technology · July 2017

DOI: 10.1111/bjet.12565

CITATIONS

0

4 authors:

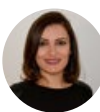

Evrim Baran

50 PUBLICATIONS 904 CITATIONS

SEE PROFILE

Aylin Albayrak Sarı

Hacettepe University

23 PUBLICATIONS 5 CITATIONS

SEE PROFILE
READS

203
Sedef Canbazoğlu Bilici

Aksaray Üniversitesi

33 PUBLICATIONS 57 CITATIONS

SEE PROFILE

Jo Tondeur

Vrije Universiteit Brussel

138 PUBLICATIONS 3,077 CITATIONS

SEE PROFILE

Some of the authors of this publication are also working on these related projects:

FEN BİLIMLERI ÖĞRETMENLERINE YÖNELIKK PROBLEME DAYALI STEM EĞITIMMI UYGULAMALARI View 


\title{
Investigating the impact of teacher education strategies on preservice teachers' TPACK
}

\section{Evrim Baran, Sedef Canbazoglu Bilici, Aylin Albayrak Sari and Jo Tondeur}

Evrim Baran, PhD is an assistant professor in the Department of Educational Sciences at Middle East Technical University. Her research interests include technology and teacher education, learning sciences, and human computer interaction. Sedef Canbazoglu Bilici, PhD is an assistant professor in the Department of Science Education at Aksaray University. Her research interests include technology integration in science education, teacher education, and technological pedagogical content knowledge. Aylin Albayrak Sari, PhD is working in the Department of Science Education at Hacettepe University. She is working on topics related to science education, teacher education, educational measurement, and developing/adapting instruments. Jo Tondeur is an assistant professor in the Interfaculty Department for Teacher Education at Vrije Universiteit Brussel. His research is situated within the field of educational innovations. Specifically, his research focuses on the integrated use of ICT in preservice teacher training and compulsory education. Address for correspondence: Evrim Baran, PhD, Department of Educational Sciences, Middle East Technical University, Dumlupinar Bulvari No: 1 Egitim Fakultesi, Egitim Bilimleri Bolumu, Orta Dogu Teknik Universitesi, Cankaya, Ankara, 06800, Turkey. Email: evrimb@gmail.com

\begin{abstract}
The purpose of this study was to examine preservice teachers' perceptions of the support their teacher education programs provide for developing their technological pedagogical content knowledge (TPACK). The research was conducted with 215 preservice teachers in the last year of teacher education programs and teaching certificate programs in three universities in Turkey. Data sources were the synthesis of qualitative evidence (SQD) scale that was validated in the Turkish context as part of this study and the TPACK-practical scale. The strategies investigated in the SQD-model included: using teacher educators as role models; reflecting on the role of technology in education; learning how to use technology by design; collaboration with peers; scaffolding authentic technology experiences; and providing continuous feedback. The linear regression analysis revealed a positive relation between teacher education strategies and preservice teachers' TPACK. Reflection and teacher educators' as role models were the most frequently used teacher education strategies in teacher education programs included in this study. Results provided recommendations for further research on the connection between the teacher education strategies and the development of preservice teachers' TPACK in teacher education programs.
\end{abstract}

\section{Introduction}

Preparing preservice teachers for effective technology integration practices in their future classrooms is considered an indispensable component of teacher education programs worldwide (Drummond \& Sweeney, 2017). A range of strategies are integrated into teacher training practices to develop preservice teachers' attitudes, knowledge and skills for effective use of classroom technologies. The most common strategies include offering technology and material development courses, establishing mentoring programs and developing online support systems (Ottenbreit-Leftwich, Glazewski, Newby, \& Ertmer, 2010). Recent research argues for a more integrated and holistic approach for the implementation of these strategies in preservice teacher education programs (Polly, Mims, Shepherd, \& Inan, 2010). In this respect, Tondeur et al. (2012) reviewed 


\section{Practitioner Notes}

What is already known about this topic

- The synthesis of qualitative evidence (SQD) strategies develop preservice teachers' effective information and communication technology (ICT) use in classrooms.

- TPACK defines teachers' knowledge of effective ICT integration in classrooms.

- TPACK-practical identifies indicators of teachers' application of their knowledge of students, subject matter, curriculum design, instruction and evaluation in ICT classrooms.

What this paper adds

- The SQD-model was validated in the Turkish teacher education context.

- Reflection and teacher educators as role models are the most frequently used teacher education strategies in teacher education programs in Turkey.

- Teacher education SQD-strategies are significant predictors of preservice teachers' TPACK-practical.

Implications for practice and/or policy

- Preservice teachers need ongoing feedback and evaluation regarding their TPACK-practical competencies in their teacher education programs.

- To maximize preservice teachers' TPACK-practical levels, the strategies included in the SQD-model can be implemented in their teacher education programs.

strategies used in teacher training programs and developed an overarching synthesis of qualitative evidence (SQD)-model that include: (1) using teacher educators as role models; (2) reflecting on the role of technology in education; (3) learning how to use technology by design; (4) collaborating with peers; (5) scaffolding authentic technology experiences; and (6), providing continuous feedback. The SQD scale developed based on this model provides a valuable instrument to assess preservice teachers' perceptions of the support they receive from their teacher education programs in terms of effective educational technology use in their future classrooms (Tondeur, van Braak, Siddiq, \& Scherer, 2016). The model also presents a guide for teacher educators to review and renew their current teacher training practices.

In the last decade, researchers extensively used the technological pedagogical content knowledge (TPACK) framework (Mishra \& Koehler, 2006) to guide the design of teacher education programs. TPACK is accepted as an important framework for defining how well teachers integrate technologies into their classrooms. To equip preservice teachers with TPACK, measurement instruments, models and conceptualizations were introduced to the literature (eg, Angeli \& Valanides, 2009). Since a "nuanced understanding of the complex relationships between technology, content, and pedagogy" (Mishra \& Koehler, 2006, p. 1029) is hidden in the transparency of spontaneous actions of teachers, an increasing number of review studies on TPACK called for new approaches for examining TPACK in practice (Chai, Koh, \& Tsai, 2013; Voogt, Fisser, Pareja Roblin, Tondeur, \& van Braak, 2013). One approach is the conceptualization of teachers' practical knowledge that situate TPACK to teacher practice and teaching experiences (Yeh, Hsu, Wu, Hwang, \& Lin, 2014).

TPACK has a dynamic structure, and researchers have used different tools and methods for understanding the knowledge in practice (Jen, Yeh, Hsu, Wu, \& Chen, 2016). One of the most common measurement tools to investigate TPACK is self-report surveys, which provide data regarding preservice teachers' self-efficacy, beliefs and attitudes. For example, the 
TPACK-practical model developed by Yeh et al. (2014) identified benchmarks and features for teachers' TPACK in practice under knowledge dimensions and pedagogical areas. TPACKpractical discusses teachers' practical knowledge developed via long-term teaching experiences with information and communication technologies (ICTs) (Ay, Karadag, \& Acat, 2015). Both SQD and TPACK-practical models provide tools to assess preservice teachers' practical knowledge and perceptions on the teacher education strategies for teacher educators. However, the relationship between how well teacher education programs implement strategies and preservice teachers' TPACK-practical development has not been extensively explored. This research aimed to examine preservice teachers' perceptions on the support their teacher education programs provide for developing their TPACK-practical. The results help to understand to what extent the strategies implemented in teacher education programs impact preservice teachers' TPACK-practical.

\section{Strategies to prepare preservice teachers' TPACK}

Teacher education programs need to prepare preservice teachers for knowledge and skills regarding effective technology integration in their future classrooms. There are different strategies of content and delivery to prepare preservice teachers for TPACK (eg, Mouza, Karchmer-Klein, Nandakumar, Ozden, \& Hu, 2014). Nonetheless, it is still unclear how teacher education programs can get a comprehensive overview of effective strategies. In this respect, Tondeur et al. (2012) reviewed 19 qualitative studies to develop an SQD-model based on content and delivery methods which best prepare preservice teachers to integrate technology in their future classrooms (see Figure 1).

According to the findings of this review, 12 key themes need to be taken into consideration in teacher education programs to prepare future teachers for technology integration. The two outward circles in the SQD-model present the conditions necessary at the institutional level, such as technology planning and leadership, training staff, access to resources and cooperation within and between the institutions. The inner circle includes micro level strategies such as using teacher educators as role models and scaffolding authentic technology experiences. The first strategy of the SQD-model (Figure 1) shows that teacher educators acting as role models proved to be

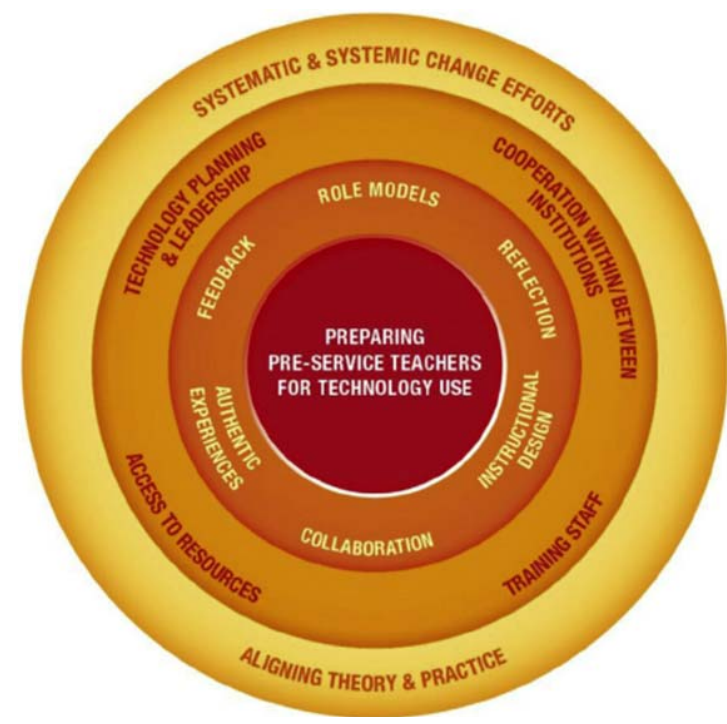

Figure 1: SQD-model to prepare preservice teachers for technology use (Tondeur et al., 2012, p. 141)

[Colour figure can be viewed at wileyonlinelibrary.com] 
an important motivator for preservice teachers' TPACK development (Strategy 1). However, simply having the participants watch examples of ICT applications is helpful but not sufficient. Preservice teachers should be able to interpret these examples in a specific educational context. Observing, discussing and reflecting collaboratively upon successful uses of technology might help them see the utility, value and feasibility of using a particular technology and/or teaching strategy (eg, Lim \& Chan, 2007), improving their ability to differentiate between action and purpose and enabling deeper and more critical thinking around integration (Strategy 2). Besides the importance of role models and reflection, research suggests that providing the opportunity to learn about technology integration by evaluating, and (re-)designing curriculum materials (Strategy 3) can also be a promising strategy (Angeli \& Valanides, 2009).

In different studies, preservice teachers stated that technology integration required additional planning and preparation because they had no prior knowledge and experience about the design of ICT-supported learning activities (eg, Polly et al., 2010). Many TPACK studies strongly support group work when designing technology-related curriculum materials (Angeli \& Valanides, 2009). According to Angeli and Valanides (2009), collaboration with peers appears to provide a low threatening learning environment for preservice teachers, thereby reducing anxiety and failure avoidance (Strategy 4). Preservice teachers may also acknowledge the importance of applying their knowledge about educational technology in authentic settings (Strategy 5). Previous research (Banas \& York, 2014) indicates that on-going and process-oriented feedback is beneficial to build preservice teachers' abilities to use technology in the classroom (Strategy 6), which has been proven to be beneficial for preservice teachers' TPACK.

\section{Developing TPACK-practical}

Examining preservice teachers' use of ICTs in instruction of a subject is of substantial importance. Yeh et al. (2014) based their TPACK-practical model on the notion that technology integration should not only be theoretical; preservice teachers should also gain authentic experiences from it. The TPACK-practical model consists of eight knowledge dimensions under five pedagogical areas. The knowledge dimensions include: (1) Using ICT to understand students, (2) using ICT to understand content, (3) planning ICT-infused curriculum, (4) using ICT representations, and (5) using ICT-integrated teaching strategies, applying ICT to instructional management, infusing ICT into teaching contexts, using ICT to assess students. The pedagogical areas include: learners, subject content, curriculum design, practical teaching and assessment (see Figure 2).

Several studies used the TPACK-practical model to investigate teachers' TPACK in practice in different subject domains (Hsu, Yeh, \& Wu, 2015; Yeh et al., 2014; Yeh, Lin, Hsu, Wu, \& Hwang, 2015). Yeh et al. (2015) categorized teachers in three TPACK-practical proficiency levels: technology-infusive (TI), technology transitional (TR) and planning and design (PD). The teachers in the TI category demonstrated higher TPACK-practical illustrating more student-centered classroom practices with technology. The researchers concluded that teachers' tendency toward student-centered instruction with ICT in the TI category pointed to the fact that TPACK-practical improves with experience. In another study, Jen et al. (2016) did not find any significant difference between preservice teachers' and experienced teachers' TPACK-practical. Research conducted in the Turkish context revealed that experienced teachers had lower TPACK-practical competency scores (Ay et al., 2015). High school teachers were found to have higher TPACKpractical competency scores compared to middle school teachers (Ay et al., 2015). Teachers from various disciplines presented the highest score in the learning area "using ICT-integrated teaching strategies," and the lowest score in the learning areas "infusing ICT into teaching contexts" (Ay et al., 2015). 


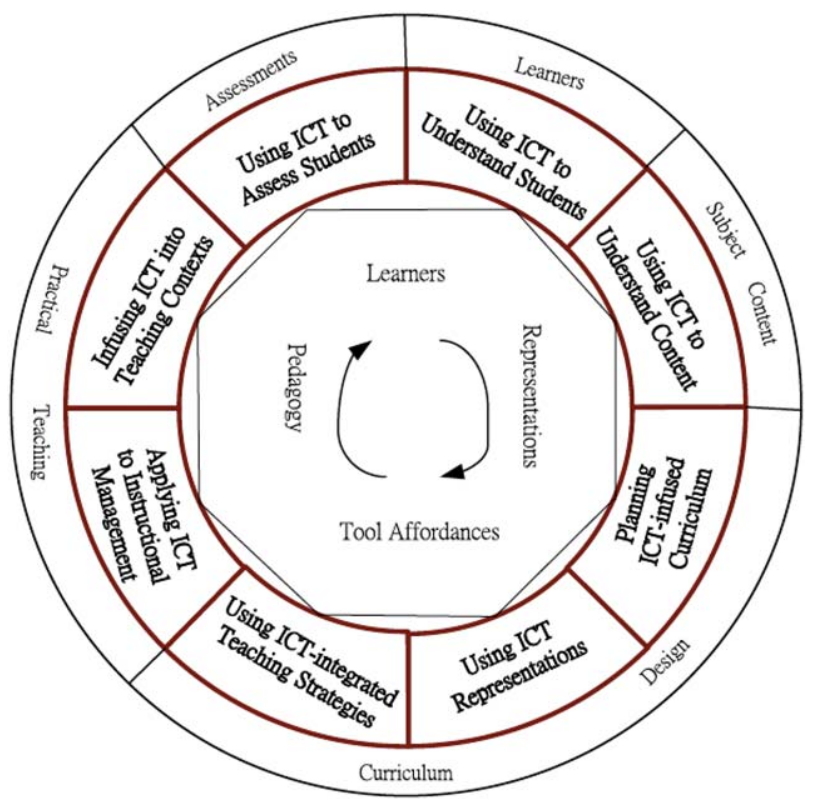

Figure 2: The TPACK-practical model (Yeh et al., 2014, p. 8) [Colour figure can be viewed at wileyonline library.com]

Purpose of the study

Preparing preservice teachers with knowledge and skills required for effective technology integration in their future classrooms requires the implementation of deliberate and systematic strategies in preservice teacher education programs. While an extensive literature exists on preservice teachers' evaluation of their own TPACK (Voogt et al., 2013), little is known about the relationship between preservice teacher education strategies and preservice teachers' TPACK-practical. The SQD and the TPACK-practical models present frameworks for such an analysis. The following research questions were examined in this study:

1. What are the preservice teachers' perceptions toward the use of ICT strategies in their teacher training institutions (SQD)?

2. What are the levels of preservice teachers' TPACK-practical?

3. To what extent do the SQD-strategies affect preservice teachers' TPACK-practical?

\section{Method}

In this study, a correlational research design was used to develop a predictive regression modeling. The explanatory correlation design, as a type of correlational research design, was used to explore "the extent to which two variables (or more) co-vary, that is, where changes in one variable are reflected in changes in the other" (Creswell, 2012, p. 340). This research design was conducted, because all participants were used as a single group and the study focus was to collect data at one point in time. Hence, the data were analyzed to reveal preservice teachers' TPACKpractical and SQD levels and determine to what extent SQD predicted their TPACK-practical levels.

\section{Participants}

The participants for this study were 215 preservice teachers (146 female, 69 male) who were enrolled in the last year of teacher education programs $(n=177)$ and teaching certificate 
Table 1: Descriptive profile of the participants

\begin{tabular}{lcc}
\hline Subscale & Frequency $(n)$ & Percentage (\%) \\
\hline Gender & & 32.1 \\
Male & 69 & 67.9 \\
Female & 146 & \\
Age & & 95.8 \\
$21-30$ & 206 & 4.2 \\
$31-40$ & 9 & \\
University & & 44.2 \\
A & 95 & 14.9 \\
B & 32 & 40.9 \\
C & 88 & \\
Department & & 22.3 \\
Science Education & 48 & 19.1 \\
Social Sciences Education & 41 & 17.2 \\
Elementary Mathematics Education & 37 & 16.3 \\
Primary Education & 35 & 7.4 \\
English Language Education & 16 & 6.5 \\
Secondary Mathematics Education & 14 & 5.6 \\
Secondary Biology Education & 12 & 4.2 \\
Secondary Chemistry Education & 9 & 1.4 \\
Secondary Physics Education & 3 & 100 \\
Total & 215 & \\
\hline
\end{tabular}

programs $(n=38)$ in three universities in Turkey. Of the 241 preservice teachers contacted for the research, 215 completed the instruments, yielding a response rate of $89 \%$. These participants studied science education ( $n=48,22.3 \%)$, social sciences education $(n=41,19.1 \%)$, elementary mathematics education $(n=37,17.2 \%)$, primary education $(n=35,16.3 \%)$, English language education $(n=16,7.4 \%)$ secondary mathematics education $(n=14,6.5 \%)$, secondary biology education $(n=12,5.6 \%)$, secondary chemistry education $(n=9,4.2 \%)$ and secondary physics education $(n=3,1.4 \%)$ (see Table 1$)$.

Data collection

The data sources included the SQD scale that was developed by Tondeur et al. (2016) and adopted to the Turkish context, as well as the TPACK-practical scale developed by Yeh et al. (2014) and adopted to the Turkish context by Ay et al. (2015). Preservice teachers enrolled in teacher education courses in Spring 2016 were invited to complete paper-and-pencil surveys, which took approximately 15-20 minutes. An independent researcher collected the data within the classrooms.

The SQD scale

The SQD scale used in this study included 24 items that are rated on a 5-point scale, ranging from 1 (totally disagree) to 5 (totally agree). The scale was developed by Tondeur et al. (2016) based on the inner circle of the SQD-model, which listed effective strategies for preparing preservice teachers for technology integration in their future classrooms (Tondeur et al., 2012). The SQD-model presented key themes necessary for preservice teacher preparation at micro (eg, using teacher educators as role models) and institutional (eg, technology planning and leadership) levels. The SQD scale included six dimensions that measured the themes concerning strategies at the micro level: (1) using teacher educators as role models (role model); (2) reflecting on the role of 
technology in education (reflection); (3) learning how to use technology by design (instructional design); (4) collaborating with peers (collaboration); (5) scaffolding authentic technology experiences (authentic experience); and (6) providing continuous feedback (feedback).

One of the most important part of adaptation studies is to have similar results that are obtained from source language and target language; in other words, to have a linguistic equivalence. In this study, a bilingual study was conducted to check whether the target language version retained all properties of the source language version. To validate the Turkish form of the SQD survey in the Turkish context, first, the scale was translated to Turkish by two researchers who had good command of English and who held PhDs in the field of educational research. These researchers met, compared the items and selected the translations for each item. The scale items in Turkish were, then, translated back to English by four people who studied educational technology in their $\mathrm{PhD}$ programs and who had their training in English. Their translations were reviewed by three researchers and necessary changes were implemented to the items. The English and Turkish versions of the survey were used with 15 preservice teachers over 2 weeks. Even though the native language of these participants was Turkish, they showed good command of English because it was the language of instruction in their teacher education program. The Pearson correlation coefficient analyzed to examine the linguistic equivalence was .83 $(p<0.05)$, showing a high correlation. Paired sample $t$-test was used to check if there was a significant difference between the items in the Turkish and English versions. No significant difference was found between the items of the two versions (see Table 2). These results showed that there was a strong and high correlation between the Turkish and English versions of the SQD, and similar results could be drawn from two the forms.

Table 2: Paired sample t-test results for linguistic equivalence

\begin{tabular}{llcccccccccc}
\hline Items & Language & $X$ & $S S$ & $T$ & $p$ & Items & Language & $X$ & $S S$ & $t$ & $p$ \\
\hline Item 1 & TR & 4.52 & 1.32 & 0.69 & 0.50 & Item 13 & TR & 3.21 & 1.26 & -2.27 & 0.04 \\
& ENG & 4.40 & 1.38 & & & & ENG & 3.85 & 1.46 & & \\
Item 2 & TR & 3.95 & 1.20 & -1.60 & 0.13 & Item 14 & TR & 3.67 & 1.53 & -2.019 & 0.061 \\
& ENG & 4.20 & 1.28 & & & & ENG & 4.32 & 1.23 & & \\
Item 3 & TR & 4.34 & 1.41 & 0.35 & 0.73 & Item 15 & TR & 3.33 & 1.20 & -2.014 & 0.061 \\
& ENG & 4.26 & 1.21 & & & & ENG & 3.88 & 1.13 & & \\
Item 4 & TR & 4.14 & 1.30 & 0.30 & 0.77 & Item 16 & TR & 3.59 & 1.38 & -1.95 & 0.07 \\
& ENG & 4.07 & 1.17 & & & & ENG & 4.09 & 1.44 & & \\
Item 5 & TR & 4.27 & 1.33 & 1.75 & 0.10 & Item 17 & TR & 3.22 & 1.39 & -1.42 & 0.18 \\
& ENG & 3.88 & 1.13 & & & & ENG & 3.60 & 1.49 & & \\
Item 6 & TR & 4.27 & 1.29 & -0.70 & 0.49 & Item 18 & TR & 3.72 & 1.45 & -0.23 & 0.82 \\
& ENG & 4.51 & 1.28 & & & & ENG & 3.78 & 1.44 & & \\
Item 7 & TR & 3.77 & 1.28 & 0.77 & 0.46 & Item 19 & TR & 3.66 & 1.41 & -1.70 & 0.11 \\
& ENG & 3.60 & 1.42 & & & & ENG & 4.14 & 1.30 & & \\
Item 8 & TR & 4.13 & 1.18 & 0.22 & 0.83 & Item 20 & TR & 3.71 & 1.24 & -0.78 & 0.44 \\
& ENG & 4.08 & 1.24 & & & & ENG & 4.01 & 1.22 & & \\
Item 9 & TR & 3.97 & 1.40 & -1.34 & 0.20 & Item 21 & TR & 3.97 & 1.40 & 0.42 & 0.68 \\
& ENG & 4.21 & 1.35 & & & & ENG & 3.85 & 1.46 & & \\
Item 10 & TR & 3.23 & 1.51 & -2.76 & 0.01 & Item 22 & TR & 3.16 & 1.42 & -1.50 & 0.15 \\
& ENG & 4.21 & 1.39 & & & & ENG & 3.66 & 1.41 & & \\
Item 11 & TR & 4.14 & 1.22 & -0.09 & 0.93 & Item 23 & TR & 3.41 & 1.37 & -1.94 & 0.07 \\
& ENG & 4.15 & 1.42 & & & & ENG & 3.91 & 1.41 & & \\
Item 12 & TR & 3.53 & 1.42 & 1.06 & 0.31 & Item 24 & TR & 3.16 & 1.42 & 0.17 & 0.87 \\
& ENG & 3.22 & 1.43 & & & & ENG & 3.10 & 1.40 & & \\
\hline
\end{tabular}


Confirmatory factor analysis (CFA) was performed to check the construct validity of the Turkish version and confirm the SQD-model defined by researchers (Tondeur et al., 2016). The fit indexes were examined for the model (chi-square/SD, RMSEA, NFI, NNFI, CFI, GFI, AGFI). As an indication of internal consistency, Cronbach's alpha reliability analysis was carried out to check the reliability of the Turkish version of the SQD survey $(r=0.97, p<0.05)$. The correlation coefficients obtained from the corrected item-total correlations ranged from 0.58 to 0.83 and were significant for all items $(p<0.05)$. These findings showed that the Turkish version of the SQD scale was reliable. The fit indexes indicated that there was a good fit between the collected data and proposed model structure.

Cronbach's alpha was used to examine the reliability of the six components and the overall scale. These components had good internal consistency: the overall scale $\alpha$ : 0.97, role model $\alpha: 0.88$, reflection $\alpha$ : 0.87, instructional design $\alpha$ : 0.89, collaboration $\alpha$ : 0.89, authentic experience $\alpha$ : 0.90, feedback $\alpha$ : 0.93. The overall Cronbach alpha coefficient showed that the scale had an excellent reliability.

\section{TPACK-practical scale}

TPACK-practical developed by Yeh et al. (2014) was used to evaluate preservice teachers' practice levels during ICT based instruction. This TPACK-practical was adapted to Turkish by Ay et al. (2015). The scale presented 22 Likert-type items, comprising five pedagogical areas. For all items, 1 represented "definitely insufficient," whereas 5 represented "definitely sufficient." For the five pedagogical areas, learners, subject content, curriculum design, practical teaching and assessment, the Cronbach Alpha coefficients were 0.71, 0.77, 0.88, 0.83 and 0.75, respectively. For the overall scale Cronbach Alpha, the coefficient was calculated to be 0.95 , which demonstrates the scale's excellent reliability.

\section{Data analysis}

Data analysis first started with descriptive statistics, which was carried out to reveal preservice teachers' perceptions about the SQD and TPACK-practical. Second, the assumptions of linear regression were checked. Third, linear regression analysis was used to examine the relationship between SQD and TPACK-practical, and whether SQD explained a significant amount of variance in TPACK-practical.

\section{Results}

Preservice teachers' perceptions toward SQD

Descriptive statistics analysis was performed to examine preservice teachers' perceptions of SQD. The means, standard deviations and Pearson correlations among the components were calculated. As shown in Table 3, participants perceived the six subscales almost similarly, with reflection and role models being attributed the highest scores.

\section{Preservice teachers' TPACK-practical levels}

Descriptive statistics analysis was performed to examine preservice teachers' TPACK-practical levels. The means, standard deviations, minimum and maximum scores are calculated. The mean total score was found to be 81.62, and standard deviation was 14.53. As seen in Table 4, the mean scores of the knowledge dimensions of the scale ranged from $1.92(S D=0.96)$ to 3.87 $(S D=1.94)$. Both the lowest score, "applying ICT to instructional management," and the highest score "using ICT to understand subject content," were under the practical teaching pedagogical area. 
Table 3: Means, standard deviations and Pearson correlations among the subscales

\begin{tabular}{llccccccccc}
\hline Subscales & \multicolumn{1}{c}{ Item numbers } & $M$ & $S D$ & 1 & 2 & 3 & 4 & 5 & 6 & $S Q D$ \\
\hline 1. AUT & (I1, I2, I3, I4) & 15.54 & 5.06 & 1 & - & - & - & - & - & - \\
2. FEE & (I5, I6, I7, I8) & 14.91 & 5.24 & $0.82^{*}$ & 1 & - & - & - & - & - \\
3. DES & (I9, I10, I11, I12) & 14.97 & 4.85 & $0.77^{*}$ & $0.77^{*}$ & 1 & - & - & - & - \\
4. REF & (I13, I14, I15, I16) & 16.32 & 4.52 & $0.71^{*}$ & $0.65^{*}$ & $0.77^{*}$ & 1 & - & - & - \\
5. ROL & (I17, I18, I19, I20) & 16.30 & 4.13 & $0.57^{*}$ & $0.57^{*}$ & $0.66^{*}$ & $0.74^{*}$ & 1 & - & - \\
6. COL & (I21, I22, I23, I24) & 15.43 & 4.88 & $0.76^{*}$ & $0.76^{*}$ & $0.81^{*}$ & $0.66^{*}$ & $0.60^{*}$ & 1 & - \\
SQD & All items & 93.48 & 24.96 & $0.89^{*}$ & $0.89^{*}$ & $0.92^{*}$ & $0.86^{*}$ & $0.78^{*}$ & $0.88^{*}$ & 1 \\
\hline
\end{tabular}

*Correlation is significant at the 0.01 level (two-tailed).

AUT, authentic experiences; COL, collaboration; DES, instructional design; FEE, feedback; REF, reflection; ROL, role model.

\section{The effect of SQD on TPACK-practical}

To test whether SQD was a significant predictor of TPACK-practical, first, the structures of the variables were analyzed. The independent variables were examined to decide which components were appropriate for regression analysis. The measurement model was established based on explanatory factor analysis (EFA), CFA and the relationships between components, which were examined as a part of the SQD scale's adaptation study. As a result of EFA, the SQD scale explained $78.57 \%$ of total variance and had six subscales, which had positive and high correlations ranging between 0.57 and $0.82(p<0.05)$ (see Table 3). The correlation coefficients obtained from the corrected item-total correlations ranged from 0.58 to 0.83 and were significant for all items $(p<0.05)$. The CFA results validated the unidimensionality of the SQD scale. Hence, the SQD total score was chosen as an independent (predictor) variable for this study, in line with the earlier evaluation of the corresponding scale (Tondeur et al., 2016).

Second, the correlations between TPACK-practical subscales were examined. The correlations coefficients ranged between 0.48 and $0.90(p<0.05)$. All subscales presented high correlations, in agreement with the validation study of the TPACK-practical. The TPACK-practical total score was chosen as a dependent (response) variable. Regression analysis was performed to determine the causal relationship between TPACK-practical and SQD, that is, the extent to which SQD explained the change observed in TPACK-practical with the coefficient of determination. Before examining the linear regression analysis, normality, linearity and homoscedasticity of residuals were checked. The histogram plot of standardized residuals showed that the residuals had an approximate normal distribution (see Figure 2). Pearson correlation analysis showed that there was a positive and moderate correlation $(r=0.54)$ between the two variables, indicating that the relationship between the two variables was linear in the normal P-P plot. The normal P-P plot of regression standardized residuals revealed that there was no tendency in the error terms. Moreover, as shown in the graph, there were no outliers affecting the linearity of the variables, and all the scores were gathered around a straight line. There was also a positive and linear relation (see Graph 2). The variance of the residuals should be same for all predicted scores. The scatter plot of standardized residuals and standardized predicted value displayed a random distribution of scores with no systematic pattern; in other words, the assumption of homoscedasticity was met (see Figure 3)

After all the assumptions were met, the linear regression analysis was conducted (see Table 5).

The linear regression analysis revealed that the SQD was a significant predictor of preservice teachers' TPACK-practical $\left(F_{(1,213)}=87.796, p=0.000\right)$. The Durbin Watson test value 


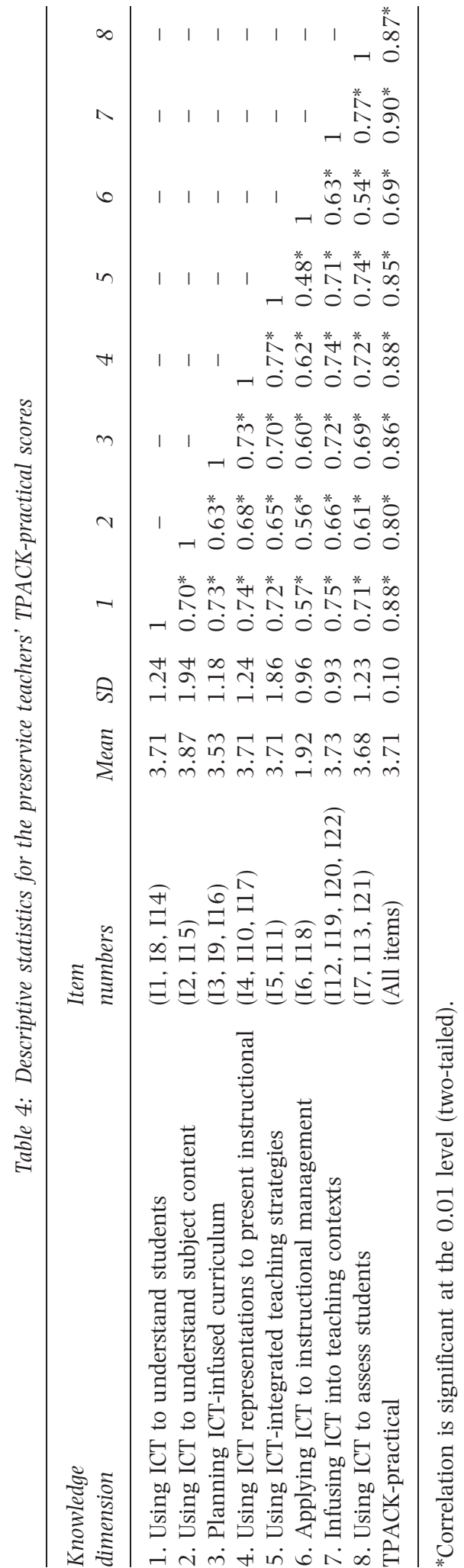




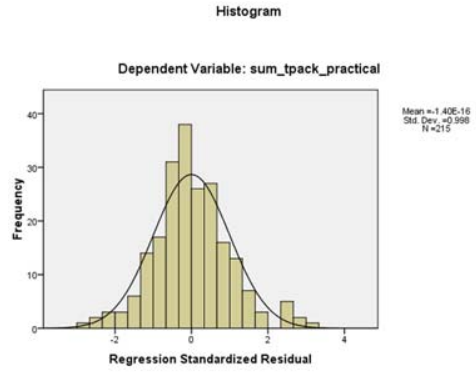

(a)

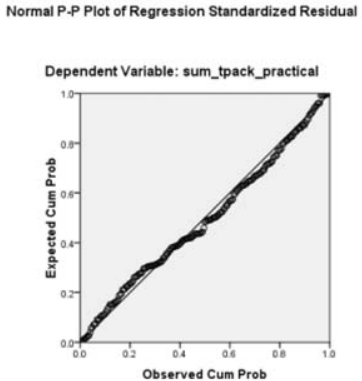

(b)

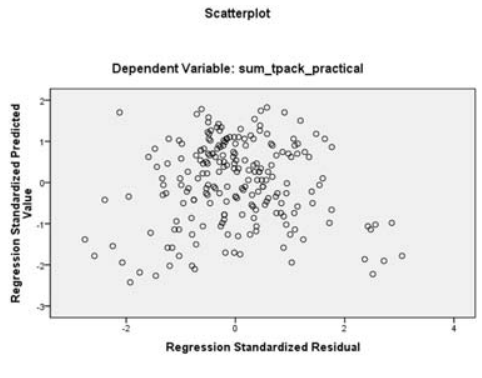

(c)

Figure 3: Graphs of linear regression analysis's assumptions: (a) Graph 1. Histogram plot of regression standardized residual (b) Graph 2. Normal P-P plot of regression standardized residual (c) Graph 3. Scatter Plot of regression standardized residuals and standardized predicted value [Colour figure can be viewed at wileyonlinelibrary.com]

$(d=1.66)$ is between the critical values $(1.5<d<2.5)$, thus it is assumed that there is no first order linear auto-correlation in the data. When the regression coefficients were analyzed, the $R^{2}$ of the model was found to be 0.292 , which means that the linear regression model explains $29.2 \%$ of the variance in the data. The linear function is " $y=52.23+0.31 \times x$." The positive value indicates an increasing relationship between TPACK-P (response variable-Y) and SQD (predictor variable-X). The equation indicates that, for every additional increase in SQD scores, a 0.31-unit increase in TPACK-practical scores is expected. The regression line explains a significant amount of variability in the TPACK-practical (see Figure 3).

\section{Concluding remarks}

This study examined the impact of preservice teachers' perceptions toward the use of ICT strategies in their teacher education programs on their levels of TPACK-practical. The study revealed that reflection and modeling were the most commonly used strategies in preservice teacher education programs. Giving preservice teachers opportunities to reflect on ICT's role in education, discussing the challenges and experiences with ICT in the classroom, as well as attitudes, are common teacher education practices (Kay, 2006). Teacher educators as role models are considered an important motivating factor behind preservice teachers' attitudes toward ICT integration in classrooms (Kaufman, 2015). Observing examples and potentials of ICT use in teacher education settings, preservice teachers noted teacher educators' modeling as another common strategy. The results also revealed that feedback and instructional design strategies were attributed the lowest scores. The literature presents similar findings, indicating the limited design and feedback opportunities provided in preservice teacher education programs (Mouza et al., 2014). Preservice teachers need ongoing feedback and evaluation regarding their competencies to help them

Table 5: Results of linear regression analysis

\begin{tabular}{lccccccc}
\hline Variable & $B$ & $\begin{array}{c}\text { Standard } \\
\text { error }\end{array}$ & $\beta$ & $t$ & $p$ & $\begin{array}{c}\text { Zero-order } \\
\text { correlation }\end{array}$ & $\begin{array}{c}\text { Partial } \\
\text { correlation }\end{array}$ \\
\hline Constant & 52.23 & 3.25 & & 16.09 & 0.00 & & \\
TPACK-practical & 0.31 & 0.03 & 0.54 & 9.37 & 0.00 & 0.54 & 0.54 \\
$R=0.540 \quad R^{2}=0.292$ & & & & & & \\
$F_{(1,213)}=87.796 \quad p=0.000$ & & & & & & \\
\hline
\end{tabular}


further develop their knowledge, skills and attitudes related to the use of ICTs in classrooms. Providing them with opportunities to design lessons with ICTs, both in their teacher education courses and field experiences, would help them develop their practical knowledge about the effective use of technology in their classrooms.

Examining preservice teachers' levels of TPACK-practical, this study showed that applying ICT to instructional management received the lowest score. Applying ICT to instructional management is a critical component of practical teaching, a process in which the student, the teacher and the context were the teaching-learning process is located interact the most (Yeh et al., 2014). Preservice teachers' knowledge of practical teaching with technology is associated with the strong connection between field practices, their coursework, and the level of technology-rich activities they experience in these environments (Polly et al., 2010). Providing preservice teachers with opportunities to implement ICTs in instructional processes during their field experiences would contribute to the development of their TPACK-practical. The results also illustrated that preservice teachers' use of ICT to understand subject content was attributed the highest score. Because preservice teachers in Turkey first take subject area courses before methods and ICT courses, they may feel more competent in using ICTs to understand their subject content.

The regression analysis showed that teacher education strategies and preservice teachers' TPACK-practical were positively associated. It can be argued that, the more teacher education programs implemented the strategies outlined in the SQD-model, the more preservice teachers' TPACK-practical levels increased. To maximize preservice teachers' TPACK-practical levels, the strategies included in the SQD-model should be experienced in their teacher education programs. The added value of this study lies in the strong connection between preservice teachers' learning experiences in their teacher education programs and their development of TPACK-practical. However, such an influence depends on how these strategies are implemented. This calls for more emphasis on the quality and variety of technology integration practices in teacher education programs (Kay, 2006). This study provided data regarding preservice teachers' TPACKpractical levels and their perceptions of the teacher education strategies, showing areas that require further emphasis in teacher education practices. Following this model, teacher education programs can design systematic and systemic technology integration practices while infusing strategies illustrated in the SQD and TPACK-practical models to the entire teacher education programs.

\section{Recommendations}

The results of this study are limited to the data collected in one academic semester in teacher training programs of three universities in Turkey. Longitudinal research may provide data regarding how the association between teacher education strategies and preservice teachers' TPACK-practical change over time, as well as the long-term impact of such strategies on TPACK development throughout different teacher education programs. Future research can also compare preservice teachers' perceptions toward use of ICT strategies and their TPACK-practical levels with a larger sample. Such comparison can reveal the needs regarding different disciplines while teaching and learning with ICT. Future research may collect in-depth data regarding teacher educators' use of strategies, challenges, and exemplary practices that connect teacher education courses with field practices. Qualitative measures such as observations and interviews could illustrate how such connections are made within online, face-to-face and hybrid preservice teacher learning environments.

\section{Statements on open data, ethics and conflict of interest}

The research data can be accessed upon request. 
Ethical permissions were obtained to collect the data from different university contexts. All participants' data were treated and stored confidentially and anonymously. All participants understood and agreed to their participation in the study prior to the beginning of the research, and were duly informed of both the purpose of the research and their right to withdraw at any moment. No incentive was provided to the participants. None of the participants considered themselves to have any disability or to be in any vulnerable circumstance prior to the beginning of the study.

There is no financial or other conflict of interest relevant to the subject of this paper.

\section{References}

Angeli, C. \& Valanides, N. (2009). Epistemological and methodological issues for the conceptualization, development, and assessment of ICT-TPCK: advances in technological pedagogical content knowledge (TPCK). Computers $\mathcal{E}$ Education, 52, 154-168.

Ay, Y., Karadag, E. \& Acat, M. B. (2015). The technological pedagogical content knowledge-practical (TPACK-practical) model: examination of its validity in the Turkish culture via structural equation modeling. Computers \& Education, 88, 97-108.

Banas, J. R. \& York, C. S. (2014). Authentic learning exercises as a means to influence preservice teachers' technology integration self-efficacy and intentions to integrate technology. Australasian Journal of Educational Technology, 30, 728-746.

Chai, C.-S., Koh, J. H.-L. \& Tsai, C.-C. (2013). A review of technological pedagogical content knowledge. Educational Technology \& Society, 16, 31-51.

Creswell, J. W. (2012). Educational research: planning, conducting, and evaluating quantitative and qualitative research (4th ed.). Boston, MA: Pearson Publication.

Drummond, A. \& Sweeney, T. (2017). Can an objective measure of technological pedagogical content knowledge (TPACK) supplement existing TPACK measures? British Journal of Educational Technology, 48, 928-939.

Hsu, Y. S., Yeh, Y. F. \& Wu, H. K. (2015). The TPACK-P framework for science teachers in a practical teaching context. In Y. S. Hsu (Ed.), Development of science teachers' TPACK (pp. 17-32). Singapore: Springer.

Jen, T. H., Yeh, Y. F., Hsu, Y. S., Wu, H. K. \& Chen, K. M. (2016). Science teachers' TPACK-Practical: standard-setting using an evidence-based approach. Computers and Education, 95, 45-62.

Kaufman, K. (2015). Information communication technology: challenges \& some prospects from preservice education to the classroom. Mid-Atlantic Education Review, 2, 1-11.

Kay, R. (2006). Evaluating strategies used to incorporate technology into pre-service education: a review of the literature. Journal of Research on Technology in Education, 38, 383-408.

Lim, C. P. \& Chan, B. C. (2007). Micro lessons in teacher education: examining pre-service teachers' pedagogical beliefs. Computers \& Education, 48, 474-494.

Mishra, P. \& Koehler, M. J. (2006). Technological pedagogical content knowledge: a framework for teacher knowledge. Teachers College Record, 108, 1017-1054.

Mouza, C., Karchmer-Klein, R., Nandakumar, R., Ozden, S. Y. \& Hu, L. (2014). Investigating the impact of an integrated approach to the development of preservice teachers' technological pedagogical content knowledge (TPACK). Computers \& Education, 71, 206-221.

Ottenbreit-Leftwich, A. T., Glazewski, K. D., Newby, T. J. \& Ertmer, P. A. (2010). Teacher value beliefs associated with using technology: addressing professional and student needs. Computers \& Education, 55, 1321-1335.

Polly, D., Mims, C., Shepherd, C. E. \& Inan, F. (2010). Evidence of impact: transforming teacher education with preparing tomorrow's teachers to teach with technology (PT3) grants. Teaching and Teacher Education, 26, 863-870.

Tondeur, J., van Braak, J., Sang, G., Voogt, J., Fisser, P. \& Ottenbreit-Leftwich, A. (2012). Preparing preservice teachers to integrate technology in education: a synthesis of qualitative evidence. Computers $\mathcal{E}$ Education, 59, 134-144.

Tondeur, J., van Braak, J., Siddiq, F. \& Scherer, R. (2016). Time for a new approach to prepare future teachers for educational technology use: its meaning and measurement. Computers \& Education, 94, 134-150. 
Voogt, J., Fisser, P., Pareja Roblin, N., Tondeur, J. \& van Braak, J. (2013). Technological pedagogical content knowledge: a review of the literature. Journal of Computer Assisted Learning, 29, 109-121.

Yeh, Y., Hsu, Y., Wu, H., Hwang, F. \& Lin, T. (2014). Developing and validating technological pedagogical content knowledge-practical (TPACK-practical) through the Delphi survey technique. British Journal of Educational Technology, 45, 707-722.

Yeh, Y. F., Lin, T. C., Hsu, Y. S., Wu, H. K. \& Hwang, F. K. (2015). Science teachers' proficiency levels and patterns of TPACK in a practical context. Journal of Science Education and Technology, 24, 78-90. 